\title{
Every single conidium in Aspergillus fumigatus caspofungin tolerant strains are intrinsically caspofungin tolerant
}

Clara Valero ${ }^{1}$, Ana Cristina Colabardini ${ }^{1}$, Patrícia Alves de Castro ${ }^{1}$, Jorge Amich $^{2,3}$, Michael J. Bromley ${ }^{3,4}$ and Gustavo H. Goldman ${ }^{*}$

${ }^{1}$ Faculdade de Ciências Farmacêuticas de Ribeirão Preto, Universidade de São Paulo, Brazil

${ }^{2}$ Mycology Reference Laboratory, National Centre for Microbiology, Instituto de Salud Carlos III (ISCIII), Majadahonda, Madrid, Spain.

${ }^{3}$ Manchester Fungal Infection Group, Division of Evolution, Infection, and Genomics, Faculty of Biology, Medicine and Health, University of Manchester, , Manchester, United Kingdom.

${ }^{4}$ Antimicrobial Resistance Network, University of Manchester, Manchester, United Kingdom.

*Corresponding author:

Dr. Gustavo Henrique Goldman

Faculdade de Ciências Farmacêuticas de Ribeirão Preto

Universidade de São Paulo

Av. do Café S/N CEP 14040-903

Ribeirão Preto, São Paulo, Brazil

e-mail: ggoldman@usp.br

Keywords: Aspergillus fumigatus, caspofungin, tolerance, drug heterogeneity

Running title: Aspergillus fumigatus caspofungin tolerance 


\section{Abstract}

Aspergillus fumigatus is a human fungal pathogen that causes a disease named aspergillosis. Echinocandins, such as the fungistatic drug caspofungin (CAS) are used as second-line therapy. Some $A$. fumigatus clinical isolates can survive and grow in higher CAS concentrations, a phenomenon known as "caspofungin paradoxical effect" (CPE). Here we investigate if CPE is due to a subpopulation of conidia produced by a CAS tolerant strain, indicative of a persistence phenotype or is caused by all the conidia which would be consistent with a tolerance phenotype. We evaluated $67 \mathrm{~A}$. fumigatus clinical isolates for CPE growth and used a novel CPE Index (CPEI) classified them as $\mathrm{CPE}^{+}(\mathrm{CPEI} \geq 0.40)$ or $\mathrm{CPE}^{-}(\mathrm{CPEI} \leq 0.20)$. Conidia produced by three $\mathrm{CPE}^{+}$clinical isolates, CEA17 (CPEl=0.52), Af293 (CPEI=0.64), CM7555 ( $\mathrm{CPEI}=0.58$ ) all showed the ability to grow in high levels of CAS while all conidia produced by the CPE isolate IFM61407 (CPEI=0.12) strain showed no evidence of tolerance. Given the importance of calcium/calcineurin/transcription factor CrzA pathway in CPE regulation, we also evaluated $\triangle c r z A^{\mathrm{At2} 93}\left(\mathrm{CPE}^{-}\right)$ and $\triangle c r z A^{\mathrm{CEA} 17}\left(\mathrm{CPE}^{+}\right)$conidia tolerance to $\mathrm{CAS}$. All $\triangle c r z A^{\mathrm{CEA} 17}$ conidia showed $\mathrm{CPE}^{+}$while $100 \%$ of $\triangle c r z A^{\mathrm{Af} 293}$ spores are $\mathrm{CPE}$. As all spores derived from an individual strain are phenotypically indistinct with respect to CPE it is likely that CPE is a genetically encoded adaptive trait that should be considered an antifungal tolerant phenotype. As the CPEI shows that the strength of the CPE is not uniform between strains we propose that the mechanisms that govern this phenomenon are multi-factorial. 


\section{Importance}

Aspergillus fumigatus is the most important human fungal pathogen causing pulmonary infections. Caspofungin (CAS) is a fungistatic drug used as a second-line therapy against aspergillosis, the group of diseases caused by $A$. fumigatus. CAS inhibits the function of Fks1 a $\beta$-1,3-glucan synthase that has a critical role in the synthesis of the cell wall. Resistance to CAS is commonly associated with mutations in $f k s 1$, however, some $A$. fumigatus clinical isolates are able to grow in the presence of higher CAS concentrations, a drug tolerance phenomenon known as the "caspofungin paradoxical effect" (CPE). Here, based on the characterization of CPE presence in a series of $A$. fumigatus clinical isolates, we demonstrate that $A$. fumigatus CAS tolerant strains do not exhibit a CAS heterogeneous response. Our results indicate that every single conidium in $A$. fumigatus CAS tolerant strains are intrinsically CAS tolerant. 


\section{Observation}

Fungal diseases are a significant health problem affecting more than 1 billion people around the world and causing more than 1.5 million deaths (1). Aspergillus fumigatus is the most important agent of fungal pulmonary infection causing a group of heterogeneous clinical diseases named aspergillosis (2). Few antifungal agents, such as the fungicidal azoles (first-line therapy, itraconazole, posaconazole, voriconazole, and isavuconazole), amphotericin $B$, and the fungistatic echinocandins (caspofungin, CAS, second-line therapy) are available to treat aspergillosis while worryingly clinical azole resistance has been increasingly reported (3-5). While azoles inhibit the ergosterol biosynthesis pathway by directly targeting the eburicol 14-demethylase Cyp51A/ERG11 (6), CAS acts by noncompetitively inhibiting the fungal $\beta-1,3-$ glucan synthase (Fks1), which is essential for the biosynthesis of $\beta-1,3$-glucan in the fungal cell wall (7). In patients suffering from invasive aspergillosis, strains resistant to the azoles have often been shown to be acquired from the environment however in those suffering from chronic forms of aspergillosis resistance typically, and frequently occurs during the course of infection (8). CAS resistance has been increasingly observed in Candida spp. (9), and although infrequently described, there are reports of $A$. fumigatus CAS resistance from patients with chronic aspergillosis (10). Mutations in specific "hotspots" of the FKS1 gene are the main genetic mechanisms of CAS resistance described in both Candida spp. and Aspergillus spp. (10, 11).

Drug tolerance has been extensively studied in bacterial pathogens, where it has been defined as the ability of all cells of an isogenic strain to survive and even grow at slow rates in the presence of drug concentrations that are greater than the minimal inhibitory concentration (MIC) (12). The term persistance is a type of tolerance that describes a phenomenon where only a sub-population of cells within an isogenic strain are tolerant. To date, the description of tolerance in fungi has focused almost exclusively on yeast-like fungi where tolerance is frequently observed as occurring in sub-populations within an isogenic strain (13-15). Very little attention has been given to defining 
drug tolerance in filamentous fungi however one adaptive phenomenon exhibited by some $A$. fumigatus clinical isolates allows them to grow and tolerate high CAS concentrations and is known as the "caspofungin paradoxical effect" (CPE). Although there are several mechanisms already described for $A$. fumigatus CPE (for reviews, see 16, 17), there is a little understanding if CPE occurs as a result of phenotypic heterogeneity within an isogenic population. Here, based on the characterization of CPE presence in a series of $A$. fumigatus clinical isolates, we demonstrate that conidia from $A$. fumigatus CAS tolerant strains do not exhibit CAS heterogeneity and hence CPE should be considered as a tolerant but not persistant phenotype.

We have investigated the CPE in 67 A. fumigatus clinical isolates (Supplementary Tables S1 and S2 at 10.6084/m9.figshare.19178888; S. Zhao, A. Martin-Vicente, A. C. Colabardini, L. P. Silva, J. R. Fortwendel, G. H. Goldman, and J. G. Gibbons, submitted for publication) and defined a CPE index $(\mathrm{CPEI})=$ average radial diameter in $\mathrm{MM}+8 \mu \mathrm{g} / \mathrm{ml}$ CAS/average radial diameter in $\mathrm{MM}$, where $\mathrm{CPEI} \geq 0.4$ are $\mathrm{CPE}^{+}$, CPEI $\geq 0.25$ and $\leq 0.4$ have an intermediate (partial) phenotype $\left(\mathrm{CPE}^{\mathrm{P}}\right)$, and $\mathrm{CPEI} \leq 0.2$ are $\mathrm{CPE}^{-}$. Figure 1A shows the heat map representing the CPEI of $67 \mathrm{~A}$. fumigatus clinical isolates grown for 5 days at $37^{\circ} \mathrm{C}$ on $\mathrm{MM}+0.125$ to $8 \mu \mathrm{g} / \mathrm{ml}$ of CAS. Radial growth in the presence of CAS is exemplified for three clinical isolates CEA17/A1163 (CPEI=0.52), CM7555 (CPEI=0.58) and IFM61407 (CPEI=0.12) (Figure 1B). It should be noted that the CPEI cannot be assessed for strains that are resistant to CAS using the drug concentrations outlined here however by adjusting the CAS concentrations the CPEI can still be calculated.

A. fumigatus sexual and asexual spores are the single developmental "cell-like"-structures with a single nucleus in the fungus. Germlings or mycelia are syncytia with several nuclei present in a common cytoplasm. Is CAS tolerance present in a "fraction" of the conidial population or in every single conidium in a single CAS-tolerant $\mathrm{CPE}^{+}$clinical isolate? In order to address this question, we have grown two $A$. fumigatus reference isolates CEA17 $(\mathrm{CPEI}=0.52)$ and $\mathrm{Af293}(\mathrm{CPE}=0.64)$ in $\mathrm{MM}$ in the presence or absence of CAS $8 \mu \mathrm{g} / \mathrm{ml}$ for 5 days at $37^{\circ} \mathrm{C}$. Then, conidia were harvested, filtered, diluted to $10^{3}$ conidia/ml and $100 \mu \mathrm{l}$ were plated them on MM (control) or MM+8 $\mu \mathrm{g} / \mathrm{ml}$ (a CPE 
concentration) (Figure 1D). After 48 hs (MM) or 72 hs (MM+CAS) of growth at $37^{\circ} \mathrm{C}$, the number of colonies $\geq 0.5 \mathrm{~cm}$ radial diameter were counted (Figure 1C), and the CAS growth index, CGI $(\%)=$ (number of colonies radial diameter $\geq 0.5 \mathrm{~cm}$ on $\mathrm{MM}+8 \mu \mathrm{g} / \mathrm{ml} \mathrm{CAS} /$ number of colonies radial diameter $\geq 0.5 \mathrm{~cm} \mathrm{MM}$ ) x 100, was determined (Figure 1C). When CEA17, Af293, and CM7555 clinical isolates were grown on either $\mathrm{MM}$ or $\mathrm{MM}+8.0 \mu \mathrm{g} / \mathrm{ml}$, we observed a CGI of 100 \% (Figure 2A, Supplementary Table S3 at 10.6084/m9.figshare.19178888). We did not observe radial diameter size heterogeneity in any of the colonies grown on $\mathrm{MM}$ or $\mathrm{MM}+8 \mu \mathrm{g} / \mathrm{ml}$ (all c. $0.5 \mathrm{~cm}$ radial diameter; Figure 2A). These results indicate that every single conidium in $A$. fumigatus $\mathrm{CPE}^{+}$strains are intrinsically CAS tolerant. We then evaluated the CGI for the clinical isolate IFM61407 strain that is CPE $^{-}$(Figures 1C). IFM61407 conidia derived from MM or $\mathrm{MM}+8.0 \mu \mathrm{g} / \mathrm{ml}$ CAS show a CGI of $0 \%$, respectively (Figure 2A, Supplementary Table S3 at 10.6084/m9.figshare.19178888).

Calcium homeostasis has been reported to play a central role in the CPE cellular response in $A$. fumigatus (18, 19, Figura 2B). CAS increases the intracellular calcium $\left(\mathrm{Ca}^{2+}\right)$ concentration activating the calcineurin-CrzA pathway (20). CrzA regulates the activation of several stress responses and cell wall modifications $(21,19)$. Interestingly, $\operatorname{crz} A$ deletion in the clinical strain Af293 results in CPE loss (22, Figure 2C), while crzA deletion in the CEA17 background is $\mathrm{CPE}^{+}(23,19$, Figure 2C), demonstrating intra-species differences or CPE heterogeneity. Differently from $\triangle c r z A^{\mathrm{CEA} 17}$ mutant, the $\triangle c r z A^{\mathrm{Af293}}$ mutant cannot activate cell wall remodeling genes upon CAS exposure, affecting its CPE (23). The CGls for $\triangle c r z A^{\mathrm{CEA} 17}$ and $\Delta c r z A^{\mathrm{Af2} 23}$ mutant strains are 100 and $0 \%$, respectively, when grown on $M M+8 \mu \mathrm{g} / \mathrm{ml}$ independently if the conidia are derived from $M M$ or $M M+8 \mu \mathrm{g} / \mathrm{ml}$ (Figure 2D, Supplementary Table S3 at 10.6084/m9.figshare.19178888). Taken together these results indicate that the transcription factor CrzA, whose deletion results in heterogeneity in the response of the CEA17 and Af293 strains to CAS does not show CPE heterogeneity since all the conidia from the $\mathrm{CPE}^{-} \triangle c r z A^{\mathrm{Af} 293}$ strain do not exhibit CPE, while all the conidia from the $\mathrm{CPE}^{+} \Delta c r z A^{\mathrm{CEA} 17}$ strain are $\mathrm{CPE}^{+}$(Figure 2D). 
Our results emphasize the view that every single conidium in an $A$. fumigatus CPE strain is able to grow and be CAS tolerant. In contrast, conidia from $A$. fumigatus strains lacking $\mathrm{CPE}$ have reduced growth in CPE concentrations, strongly indicating that there are no $A$. fumigatus CAS tolerant subpopulations. As a conclusion, A. fumigatus CPE is a homogeneous trait within an isogenic population while CPE heterogeneity exists between strains.

\section{Acknowledgements}

We thank Fundação de Amparo à Pesquisa do Estado de São Paulo (FAPESP) 2018/00715-3 (CV), 2017/07536-4 (ACC), 2016/12948-7 (PAC) and 2016/07870-9 (GHG), and Conselho Nacional de Desenvolvimento Científico e Tecnológico (CNPq) 301058/2019-9 and 404735/2018-5 (GHG), both from Brazil, and National Institutes of Health/National Institute of Allergy and Infectious Diseases (R01Al153356), from the USA. This work was also supported by the Wellcome Trust grant number 219551/Z/19/Z and 208396/Z/17/Z to M.B.

\section{References}

1. Brown GD, Denning DW, Gow NA, Levitz SM, Netea MG, White TC. 2012. Hidden killers: human fungal infections. Sci Transl Med 4:165rv13.

2. Arastehfar A, Carvalho A, Houbraken J, Lombardi L, Garcia-Rubio R, Jenks JD, Rivero-Menendez O, Aljohani R, Jacobsen ID, Berman J, Osherov N, Hedayati MT, Ilkit M, Armstrong-James D, Gabaldon T, Meletiadis J, Kostrzewa M, Pan W, Lass-Florl C, Perlin DS, Hoenigl M. 2021. Aspergillus fumigatus and aspergillosis: From basics to clinics. Stud Mycol 100:100115.

3. Ostrosky-Zeichner L, Al-Obaidi M. 2017. Invasive fungal infections in the intensive care unit. Infect Dis Clin North Am 31:475-487. 
4. Perfect JR. 2017. The antifungal pipeline: a reality check. Nat Rev Drug Discov 16:603-616.

5. Robbins N, Caplan T, Cowen LE. 2017. Molecular evolution of antifungal drug resistance. Annu Rev Microbiol 71:753-775.

6. Warrilow AG, Parker JE, Price CL, Nes WD, Kelly SL, Kelly DE. 2015. In vitro biochemical study of CYP51-mediated azole resistance in Aspergillus fumigatus. Antimicrob Agents Chemother 59:7771-8.

7. Perlin DS. 2015. Mechanisms of echinocandin antifungal drug resistance. Ann N Y Acad Sci 1354:1-11.

8. Garcia-Rubio R, Cuenca-Estrella M, Mellado E. 2017. Triazole resistance in Aspergillus species: an emerging problem. Drugs 77:599-613.

9. Shields RK, Nguyen MH, Clancy CJ. 2015. Clinical perspectives on echinocandin resistance among Candida species. Curr Opin Infect Dis 28:514-22.

10. Jimenez-Ortigosa C, Moore C, Denning DW, Perlin DS. 2017. Emergence of echinocandin resistance due to a point mutation in the fks1 gene of Aspergillus fumigatus in a patient with chronic pulmonary aspergillosis. Antimicrob Agents Chemother 61 (12):e01277-17.

11. Wiederhold NP. 2016. Echinocandin resistance in Candida species: a review of recent developments. Curr Infect Dis Rep 18:42.

12. Brauner A, Fridman O, Gefen O, Balaban NQ. 2016. Distinguishing between resistance, tolerance and persistence to antibiotic treatment. Nat Rev Microbiol 14:320-30.

13. Delarze E, Sanglard D. 2015. Defining the frontiers between antifungal resistance, tolerance and the concept of persistence. Drug Resist Updat 23:12-19.

14. Berman J, Krysan DJ. 2020. Drug resistance and tolerance in fungi. Nat Rev Microbiol 18:319-331.

15. Ben-Ami R, Kontoyiannis DP. 2021. Resistance to antifungal drugs. Infect Dis Clin North Am 35:279-311.

16. Aruanno M, Glampedakis E, Lamoth F. 2019. Echinocandins for the treatment of invasive aspergillosis: from laboratory to bedside. Antimicrobial agents and chemotherapy 63(8) :e00399-19. 
17. Papon N, Morio F, Sanglard D. 2020. Signaling pathways governing the caspofungin paradoxical effect in Aspergillus fumigatus. mBio 11(4) :e01816-20.

18. Juvvadi PR, Munoz A, Lamoth F, Soderblom EJ, Moseley MA, Read ND, Steinbach WJ. 2015. Calcium-mediated induction of paradoxical growth following caspofungin treatment is associated with calcineurin activation and phosphorylation in Aspergillus fumigatus. Antimicrobial agents and chemotherapy 59(8):4946-55.

19. Ries LNA, Rocha MC, de Castro PA, Silva-Rocha R, Silva RN, Freitas FZ, de Assis LJ, Bertolini MC, Malavazi I, Goldman GH. 2017. The Aspergillus fumigatus CrzA transcription factor activates chitin synthase gene expression during the caspofungin paradoxical effect. mBio 8 (3):e00705-17.

20. Park HS, Lee SC, Cardenas ME, Heitman J. 2019. Calcium-calmodulincalcineurin signaling: a globally conserved virulence cascade in eukaryotic microbial pathogens. Cell Host Microbe 26:453-462.

21. Soriani FM, Malavazi I, da Silva Ferreira ME, Savoldi M, Von Zeska Kress MR, de Souza Goldman MH, Loss O, Bignell E, Goldman GH. 2008. Functional characterization of the Aspergillus fumigatus CRZ1 homologue, CrzA. Mol Microbiol 67:1274-91.

22. Fortwendel JR, Juvvadi PR, Perfect BZ, Rogg LE, Perfect JR, Steinbach WJ. 2010. Transcriptional regulation of chitin synthases by calcineurin controls paradoxical growth of Aspergillus fumigatus in response to caspofungin. Antimicrobial agents and chemotherapy. 54(4):1555-63.

23. Colabardini AC, Wang F, Dong Z, Pardeshi L, Rocha MC, Costa JH, Dos Reis TF, Brown A, Jaber QZ, Fridman M, Fill T, Rokas A, Malavazi I, Wong $\mathrm{KH}$, Goldman GH. 2022. Heterogeneity in the transcriptional response of the human pathogen Aspergillus fumigatus to the antifungal agent caspofungin. Genetics 220 (1):iyab183. 
bioRxiv preprint doi: https://doi.org/10.1101/2022.02.17.480978; this version posted February 19, 2022. The copyright holder for this preprint (which was not certified by peer review) is the author/funder. All rights reserved. No reuse allowed without permission. 


\section{Figure legends}

Figure 1 - Distribution of $A$. fumigatus CAS tolerance in 67 clinical isolates and definition of CPE index (CPEI) and CAS Growth Index (CGI). (A) Heat map depicting the CPE Index $(\mathrm{CPEI})=$ radial diameter in $\mathrm{MM}+8 \mu \mathrm{g} / \mathrm{ml}$ $\mathrm{CAS} /$ radial diameter in $\mathrm{MM}$, where $\mathrm{CPEI} \geq 0.4$ are $\mathrm{CPE}^{+}, \mathrm{CPEI} \geq 0.25$ and $\leq 0.4$ are partially $\mathrm{CPE}^{+}\left(\mathrm{CPE}^{\mathrm{P}}\right)$, and $\mathrm{CPEI} \leq 0.2$ are $\mathrm{CPE}^{-}$. Heat map scale and gene identities are indicated. Hierarchical clustering was performed in $\mathrm{MeV}$ (http://mev.tm4.org/), using Pearson correlation with complete linkage clustering. (B) Growth of A. fumigatus CEA17, CM7555, and IFM61407 clinical isolates on $\mathrm{MM}$ and $\mathrm{MM}+\mathrm{CAS}$ (increasing concentrations). The strains were grown for 5 days at $37{ }^{\circ} \mathrm{C}$. (C) Scheme showing how the CAS Growth Index (CGl) was calculated. A. fumigatus isolates were grown on $\mathrm{MM}$ or $\mathrm{MM}+8 \mu \mathrm{g} / \mathrm{ml}$ for 5 days at $37{ }^{\circ} \mathrm{C}$. Conidia were harvested, filtered, diluted to $10^{3} \mathrm{sp} / \mathrm{ml}$ and $100 \mu \mathrm{l}$ were plated in $\mathrm{MM}$ or $\mathrm{MM}+8 \mu \mathrm{g} / \mathrm{ml}$ and incubated for 2 or 3 days at 37 ${ }^{\circ} \mathrm{C}$. The number of colonies were counted in both treatments and determined the CGI as follows: $\mathrm{CGI}(\%)=$ (number of colonies radial diameter $\geq 0.5 \mathrm{~cm}$ on $\mathrm{MM}+8 \mu \mathrm{g} / \mathrm{ml} \mathrm{CAS} /$ number of colonies radial diameter $\geq 0.5 \mathrm{~cm} \mathrm{MM)} \times 100$.

Figure 2 - CAS growth index (CGI) for A. fumigatus clinical isolates. (A) CEA17, Af293, CM7555, and IFM61407 clinical isolates were grown on MM and $\mathrm{MM}+8 \mu \mathrm{g} / \mathrm{ml}$ of CAS for 5 days at $37{ }^{\circ} \mathrm{C}$. Conidia were harvested, filtered, diluted to $10^{3} \mathrm{sp} / \mathrm{ml}$ and $100 \mu \mathrm{l}$ were plated in $\mathrm{MM}$ or $\mathrm{MM}+8 \mu \mathrm{g} / \mathrm{ml}$ and incubated for 2 or 3 days at $37{ }^{\circ} \mathrm{C}$. The number of colonies were counted in both treatments and the $\mathrm{CGl}$ was determined. (B) Scheme showing the calcium/calcineurin/CrzA pathway. Upon CAS cell wall damage, calcium concentrations increase in the cytoplasm by calcium transport or mobilization of endogenous calcium deposits. Calcium binds to calmodulin, which activates calcineurin that directly dephosphorylates CrzA, resulting in its translocation to the nucleus. CrzA binds to calcineurin-dependent response elements (CDRE) promoters, activating the transcriptional programs that promote stress tolerance. (C) CEA17, Af293, $\Delta c r z A^{\mathrm{CEA} 17}$, and $\Delta c r z A^{\mathrm{Af2} 293}$ strains were grown on 
$\mathrm{MM}$ and $\mathrm{MM}+\mathrm{CAS}$ for 5 days at $37^{\circ} \mathrm{C}$. (D) $\triangle c r z A^{\mathrm{CEA} 17}$ and $\triangle c r z A^{\mathrm{Af2} 93}$ strains were grown on $\mathrm{MM}$ and $\mathrm{MM}+\mathrm{CAS}$ for 5 days at $37^{\circ} \mathrm{C}$. Conidia were harvested, filtered, diluted to $10^{3} \mathrm{sp} / \mathrm{ml}$ and $100 \mu$ l were plated in $\mathrm{MM}$ or $\mathrm{MM}+8 \mu \mathrm{g} / \mathrm{ml}$ and incubated for 2 or 3 days at $37^{\circ} \mathrm{C}$. The number of colonies were counted in both treatments and the CGI was determined. 
A.

0.0

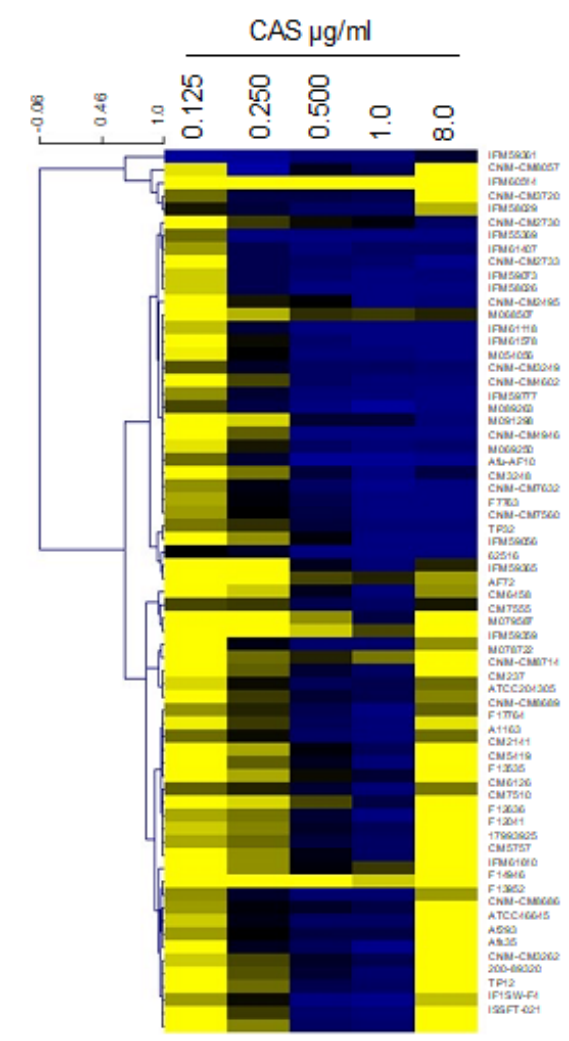

B.

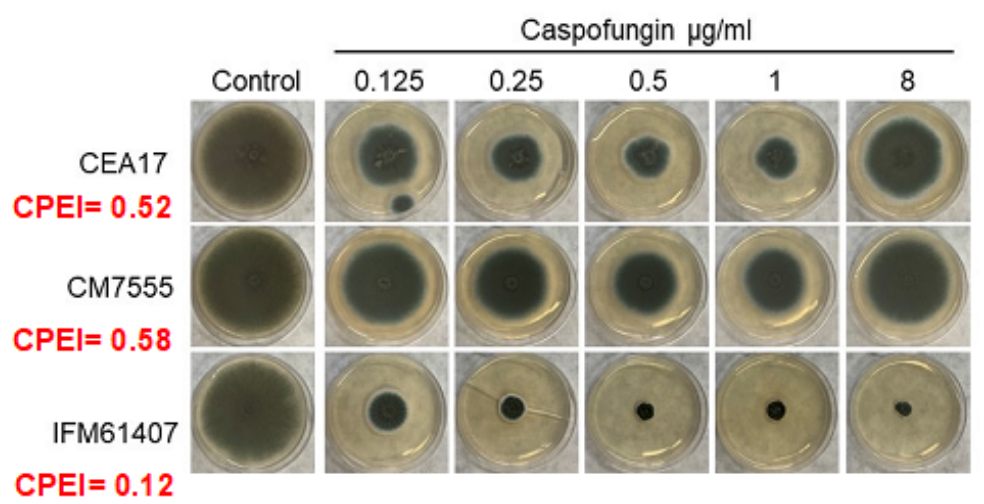

C.

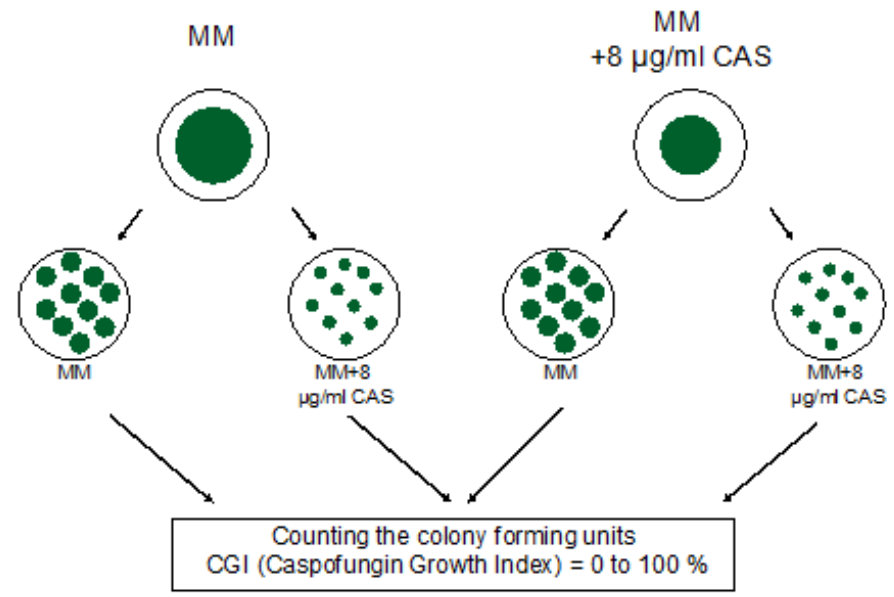




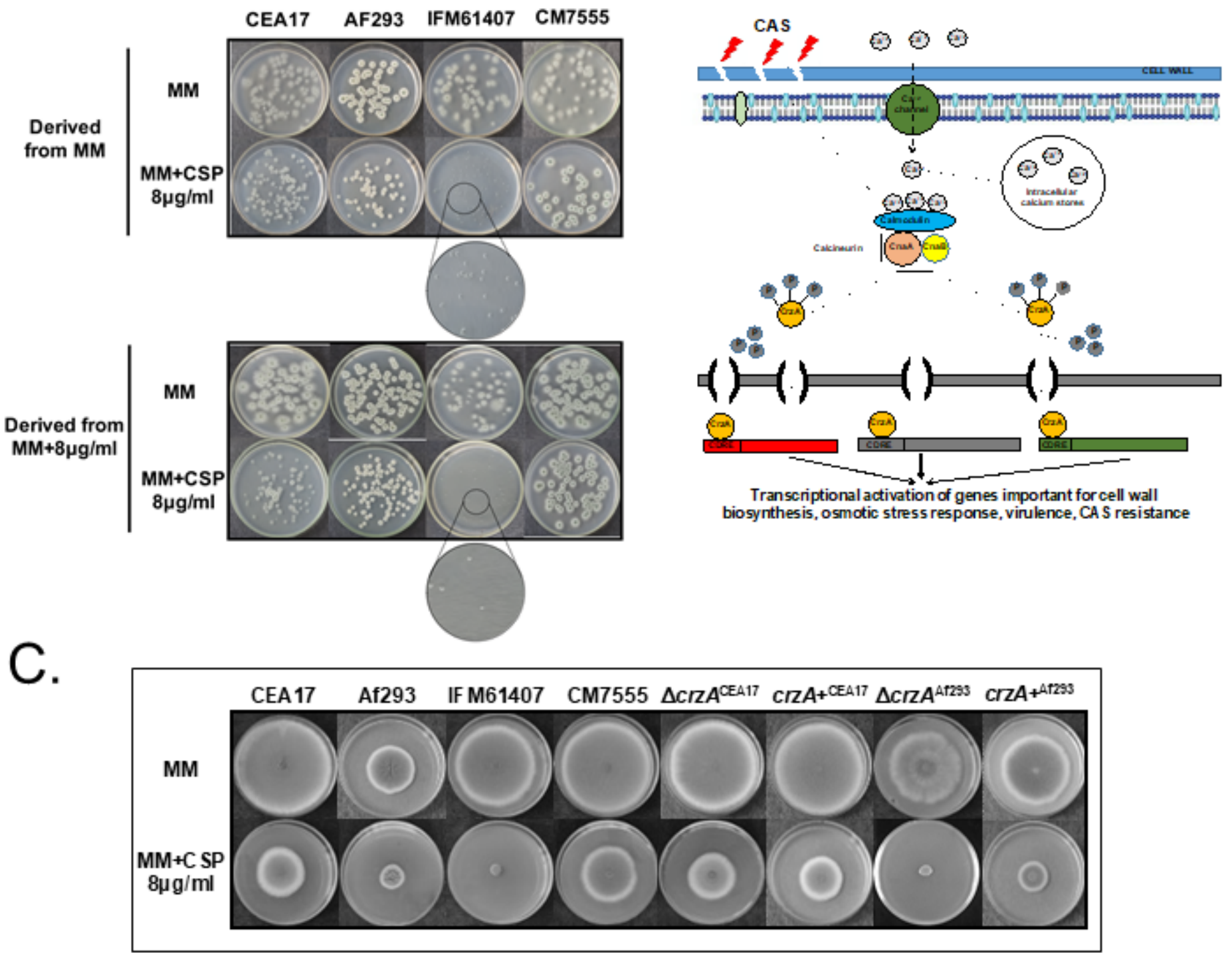

D.

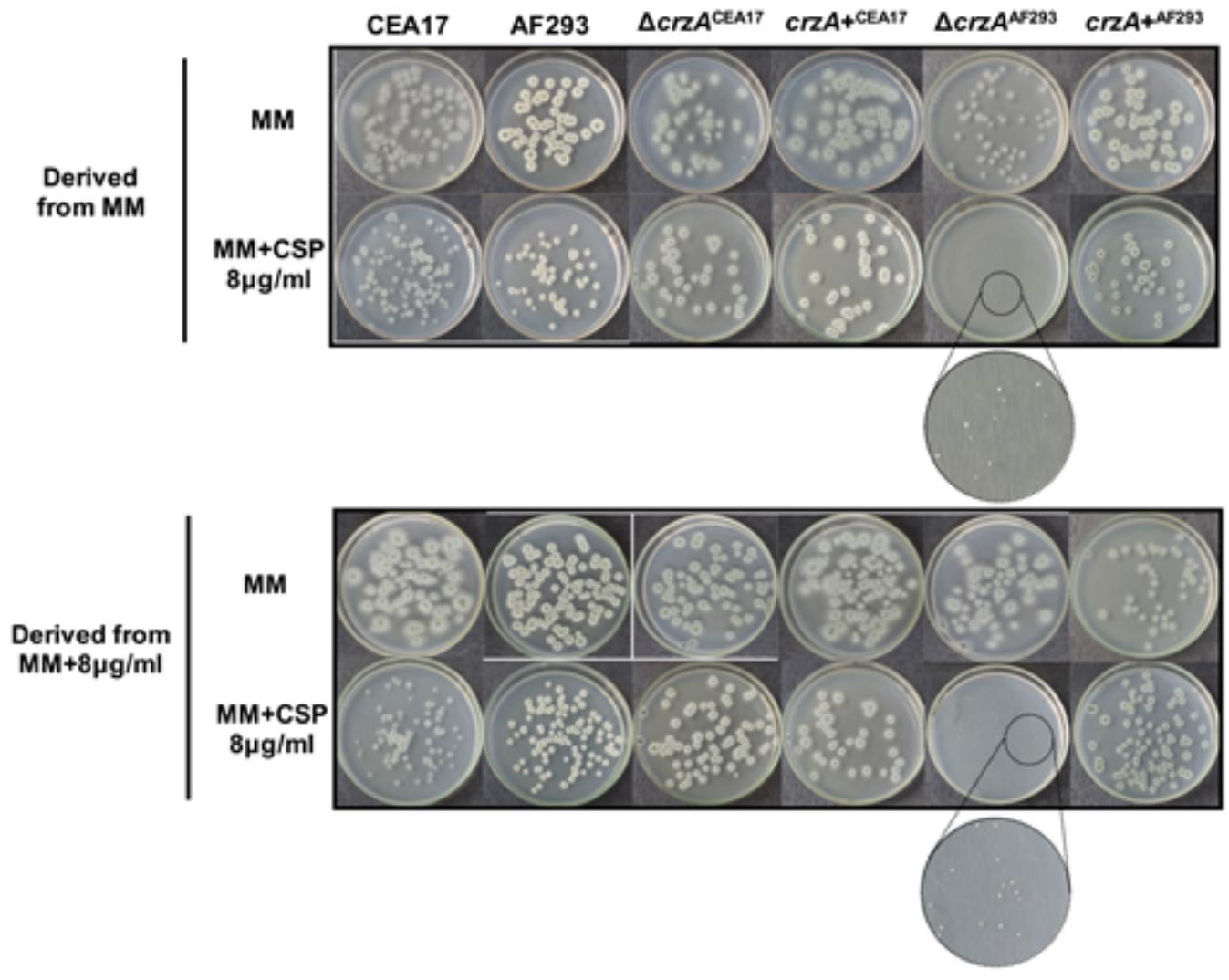

